\title{
Medical Image of the Month and Brief Review: Aspiration Pneumonia in an Intubated Patient with COVID-19
}
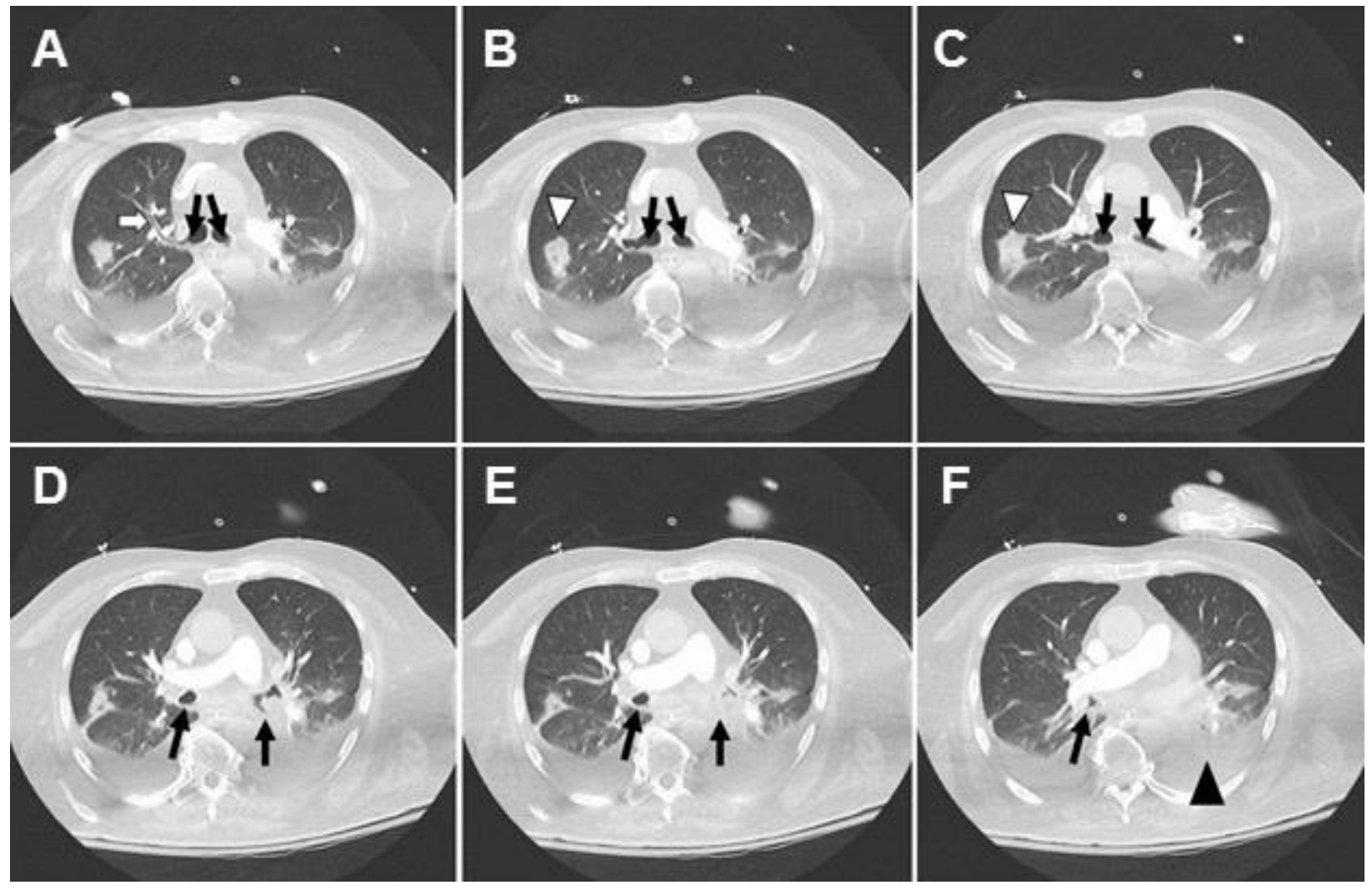

Figure 1. Severe aspiration changes on CT. Bronchial wall thickening (white arrow) could barely be perceived elsewhere given the dense layering secretions (black arrows) in bilateral mainstem bronchi and filling the dependent segmental bronchi. Atelectatic collapse (black arrowhead) can be seen distal to the obstructed bronchi. Rounded consolidation (white arrowhead) as seen later in the course of SARS2 COVID-19.

A woman in her 60's likely acquired COVID-19 through community transmission. When she developed respiratory distress, she came to the emergency department, was found to have abnormalities on chest x-ray and was intubated, testing positive on COVID-19 PCR. She developed worsening hypoxia over the course of one night after a fairly stable ICU course. CT was obtained and demonstrated severe aspiration changes including bronchial filling and collapse of the dependent lower lobes. Increased attention to suctioning helped with the desaturations, and she eventually recovered and was extubated. This case serves as a reminder to ensure adequate suctioning while patients are intubated to prevent aspiration, obstruction and related ventilator-associated pneumonia. 


\section{Discussion}

Aspiration is a relatively common event which typically resolves with no clinical sequelae. In fact, recent studies have estimated that up to $50 \%$ of healthy adults aspirate while in their sleep (1). Pulmonary symptoms of aspiration generally only occur when there is compromise to the usual defenses that protect the lower airways (cough reflex, glottis closure, etc.) and when an inoculum is introduced which has a direct toxic effect on the lower airways, resulting in inflammation. Common predisposing conditions which can lead to aspiration include reduced consciousness (commonly seen in patients with alcohol abuse or IV drug use), dysphagia from neurologic deficits, disorders of the upper Gl tract, or mechanical disruption of glottis closure due to endotracheal intubation, bronchoscopy, endoscopy, or NG feeding $(2,3)$. Endotracheal intubation is a key risk factor in ventilator associated pneumonia (4). This brief review will focus on ventilator-associated pneumonia.

Overview and epidemiology: Ventilator-associated pneumonia is defined as new onset pneumonia at least 48 hours following intubation. Despite being frequently thought of as partially protective, the presence of an endotracheal tube may actually serve as a mechanism of transport of organisms from the oropharyngeal tract (most commonly) or Gl tract (less commonly) to the lung $(5,6)$. Recent data from 2012 to 2013 suggest that the percentage of patients on ventilator support who go on to acquire aspiration pneumonia is $9.7 \%$ (7). Common pathogens associated with this condition include aerobic gram-negative bacilli (Escherichia coli, Klebsiella pneumoniae, Enterobacter spp, Pseudomonas aeruginosa, Acinetobacter spp) or grampositive cocci including MRSA and Streptococcus Pneumoniae.

Prevention: Patients should be placed in the semi-recumbent position (45 degrees) and have intermittent (every 3-6 hours) or continuous subglottic drainage $(8,9)$. Studies have found there isn't a significant difference in clinical outcomes between intermittent and continuous drainage and that intermittent drainage may be associated with less adverse effects (10). The use of acid reducing agents should also be avoided, although sucralfate use decreased ICU-acquired pneumonia (11). Gastric volume monitoring had long been the standard of clinical practice with an aim to prevent vomiting and subsequent aspiration, however recent studies have suggested that gastric volume monitoring correlates poorly with aspiration risk and may lead to a decrease in caloric delivery $(12,13)$.

\section{Symptoms/Signs}

- Important signs include fever, tachypnea, increased purulent secretions or hemoptysis; systemic signs including encephalopathy or sepsis may also be present (12).

- Ventilator: Reduced tidal volume, increased inspiratory pressures

- Labs: worsening hypoxemia, leukocytosis

- Imaging: 
- New or progressive infiltrates on CXR commonly with alveolar infiltrates or silhouetting of adjacent solid organs

- Air bronchograms are common

\section{Treatment}

Empiric treatment choices should be guided by local distribution of pathogens and susceptibility of those pathogens to antimicrobials (14-16). Treatment options should also take into consideration the likelihood of MDR organisms or MRSA. In a metaanalysis of 15 studies, factors associated with an increased risk of MDR VAP were IV antibiotics in the last 90 days, $>5$ days of hospitalization prior to onset of symptoms, septic shock on presentation of VAP, ARDS before VAP, and renal replacement therapy prior to VAP. Risk factors for MRSA include treatment in units where $>10$ to $20 \%$ of $S$. Aureus isolates are methicillin resistant, treatment in a unit where prevalence of MRSA is not known, or prior history of MRSA infection. In the absence of risk factors for MDR or MRSA, patients with VAP should receive one agent that has activity against Pseudomonas, other gram-negative bacilli, and MSSA. Patients with risk factors for MDR or MRSA should receive two agents with activity against $P$. Aeruginosa and other gram-negative bacilli and one agent with activity against MRSA (15). An algorithm guiding specific regimens for treatment of VAP can be found on UpToDate's article: Treatment of hospital-acquired and ventilator-associated pneumonia in adults (17).

Jeremy P. Head BS and Michael C. Larson MD

Department of Medical Imaging

University of Arizona

Tucson, AZ USA

\section{References}

1. Huxley EJ, Viroslav J, Gray WR, Pierce AK. Pharyngeal aspiration in normal adults and patients with depressed consciousness. Am J Med. 1978;64(4):564-568. [CrossRef] [PubMed]

2. Lo WL, Leu HB, Yang MC, Wang DH, Hsu ML. Dysphagia and risk of aspiration pneumonia: A nonrandomized, pair-matched cohort study. J Dent Sci. 2019;14(3):241-247. [CrossRef] [PubMed]

3. Mandell LA, Niederman MS. Aspiration Pneumonia. N Engl J Med. 2019;380(7):651663. [CrossRef] [PubMed]

4. Rouzé $A$, Jaillette $E$, Nseir $S$. Relationship between microaspiration of gastric contents and ventilator-associated pneumonia. Ann Transl Med. 2018;6(21):428. [CrossRef] [PubMed]

5. Garrouste-Orgeas M, Chevret S, Arlet G, et al. Oropharyngeal or gastric colonization and nosocomial pneumonia in adult intensive care unit patients. A prospective study based on genomic DNA analysis. Am J Respir Crit Care Med. 1997;156(5):16471655. [CrossRef] [PubMed] 
6. Jaillette E, Girault C, Brunin G, et al. Impact of tapered-cuff tracheal tube on microaspiration of gastric contents in intubated critically ill patients: a multicenter cluster-randomized cross-over controlled trial. Intensive Care Med. 2017;43(11):1562-1571. [CrossRef] [PubMed]

7. Metersky ML, Wang Y, Klompas M, Eckenrode S, Bakullari A, Eldridge N. Trend in Ventilator-Associated Pneumonia Rates Between 2005 and 2013. JAMA. 2016;316(22):2427-2429. [CrossRef] [PubMed]

8. Wang L, Li X, Yang Z, et al. Semi-recumbent position versus supine position for the prevention of ventilator-associated pneumonia in adults requiring mechanical ventilation. Cochrane Database Syst Rev. 2016;2016(1):CD009946. [CrossRef] [PubMed]

9. Caroff DA, Li L, Muscedere J, Klompas M. Subglottic Secretion Drainage and Objective Outcomes: A Systematic Review and Meta-Analysis. Crit Care Med. 2016;44(4):830-840. [CrossRef] [PubMed]

10. Mao Z, Gao L, Wang G, et al. Subglottic secretion suction for preventing ventilatorassociated pneumonia: an updated meta-analysis and trial sequential analysis. Crit Care. 2016;20(1):353. Published 2016 Oct 28. [CrossRef] [PubMed]

11. Alquraini M, Alshamsi $\mathrm{F}$, Møller $\mathrm{MH}$, et al. Sucralfate versus histamine 2 receptor antagonists for stress ulcer prophylaxis in adult critically ill patients: A meta-analysis and trial sequential analysis of randomized trials. J Crit Care. 2017;40:21-30. [CrossRef] [PubMed]

12. Meduri GU. Diagnosis and differential diagnosis of ventilator-associated pneumonia. Clin Chest Med. 1995;16(1):61-93. [PubMed]

13. McClave SA, Lukan JK, Stefater JA, et al. Poor validity of residual volumes as a marker for risk of aspiration in critically ill patients. Crit Care Med. 2005;33(2):324330. [CrossRef] [PubMed]

14. Kalil AC, Metersky ML, Klompas M, et al. Executive Summary: Management of Adults With Hospital-acquired and Ventilator-associated Pneumonia: 2016 Clinical Practice Guidelines by the Infectious Diseases Society of America and the American Thoracic Society [published correction appears in Clin Infect Dis. 2017 May 1;64(9):1298] [published correction appears in Clin Infect Dis. 2017 Oct 1;65(7):1251]. Clin Infect Dis. 2016;63(5):575-582. [CrossRef] [PubMed]

15. Beardsley JR, Williamson JC, Johnson JW, Ohl CA, Karchmer TB, Bowton DL. Using local microbiologic data to develop institution-specific guidelines for the treatment of hospital-acquired pneumonia. Chest. 2006;130(3):787-793. [CrossRef] [PubMed]

16. Jones RN. Microbial etiologies of hospital-acquired bacterial pneumonia and ventilator-associated bacterial pneumonia [published correction appears in Clin Infect Dis. 2010 Nov 1;51(9):1114]. Clin Infect Dis. 2010;51 Suppl 1:S81-S87. [CrossRef] [PubMed]

17. Klompas M. Treatment of hospital-acquired and ventilator-associated pneumonia in adults. UpToDate. July 31, 2020. Available at: https://www.uptodate.com/contents/treatment-of-hospital-acquired-and-ventilatorassociated-pneumonia-in-adults (requires subscription). 